\title{
Peertechz
}

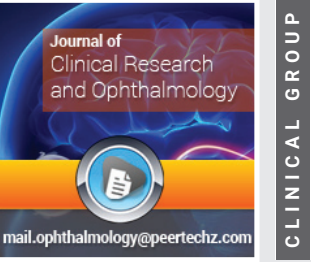

\section{Comparative study of visual results obtained with two Trifocal lens models in} cataract surgery

\author{
Alfredo Amigó-Francés ${ }^{1}$, Alfredo Castillo-Gómez', David \\ Carmona-González ${ }^{2}$, Paula Martínez-Sorribes ${ }^{2}$ and Alfredo \\ Amigó2* \\ 'Department of Ophtalmology, University Hospital Quironsalud Madrid, Spain \\ ${ }^{2}$ Instituto Oftalmológico Amigó, Santa Cruz de Tenerife, Spain
}

Received: 07 July, 2020

Accepted: 15 July, 2020

Published: 16 July, 2020

*Corresponding author: Alfredo Amigó, MD, PhD, Instituto Oftalmológico Amigó, Santa Cruz de Tenerife, 003, Spain. Email: amigo@ioamigo.com ORCID: http://orcid.org/0000-0002-8905-8801

Keywords: Multifocal intraocular lens; Trifocal Intraocular lens; Contrast sensitivity; Patient satisfaction

https://www.peertechz.com

Check for updates

\section{Abstract \\ Purpose: To compare visual performance and Contrast Sensitivity (CS) outcomes, patient satisfaction and spectacle independence in patients implanted with two Models of trifocal Intraocular Lenses (MIOLs). \\ Methods: This non-randomized prospective clinical study included 40 eyes of 20 patients undergoing cataract surgery with bilateral implantation of two different MIOLs, the trifocal Fine Vision MIOL (20 eyes) (PhysIOL, Liège, Belgium) and the trifocal Acriva Trinova MIOL (20 eyes) (VSY, Biotechnology, The Nederlands). Visual results, CS and patient satisfaction were evaluated 3 months after surgery. \\ Results: There was no statistically significant difference between groups regarding distance and intermediate visual acuity. Finevision showed better near visual outcomes than Acriva Trinova $(\mathrm{p}<0.033$ ). Both MIOLs provided similar CS within normal age ranges. Satisfaction test performed on uncorrected patients showed a}

variable presence of tolerable dysphotopsic phenomena with both MIOLs.

Conclusions: When postoperative emmetropia was achieved, both MIOLs provided good outcomes for distance and intermediate vision with no differences in contrast sensitivity. Fine Vision MIOL gave better near visual acuity results. There were tolerable dysphotopsic phenomena in both groups.

\section{Summary}

Comparing the Acriva Trinova trifocal IOL and the Fine Vision trifocal, both provided good visual outcomes, with the Acriva Trinova showing superior intermediate visual acuity at $60 \mathrm{~cm}$ and Fine Vision superior near visual acuity at $40 \mathrm{~cm}$.

\section{Introduction}

Lens surgery is one of the most frequently performed surgical procedures worldwide [1].

Whether refractive surgery of clear lens or cataract surgery, when the implanted Intraocular Lens (IOL) is monofocal it usually provides excellent vision for a single focus [2]. To avoid the inconvenience of needing glasses after surgery, so-called
Multifocal Intraocular Lenses (MIOL) were designed to divide the incoming rays of light into the eye in different foci. These MIOL can present a refractive or diffractive optics design [3]. Diffractive MIOL are characterized by optical platforms with a multitude of concentric rings with a specific separation and height which results in steps that favor and cause the diffraction of the wave front, which allows to focus at different distances [4]. 
Several clinical studies confirm the significant visual improvement of bifocal IOL for near vision compared to obtained with monofocal lenses and without significant affectation of uncorrected distant vision $[3,5,6]$. The disadvantage of bifocal LIOMs is that by having one focal point for near distance and another one for far distance, they offer a good vision only in these two distances and not in an intermediate vision thus affecting tasks such as the use of computers or musical scores among others [7-11]. Bifocal IOL limitation in intermediate vision has been the main motor of the development and the introduction of trifocal MIOL. Trifocal MIOL commercially available since 2010, are characterized by incorporating a third focus that provides better intermediate vision while maintaining close and distant vision [11-13].

Among the current trifocal MIOL, FineVision model (PhysIOL, Liège, Belgium) due to its particular diffractive design $^{12}$ is widely used in our environment. Using a stepped optical topography [14], offers an improvement in intermediate vision between 60 and $80 \mathrm{~cm}$ without detriment to near or far vision $[13,15]$

Even with the most advanced designs, after implantation of MIOL, visual alterations can occur, such as a decrease in contrast sensitivity, glare, blurred vision or nocturnal halos [6,16-18]. In addition, it is necessary to obtain very precise results, avoiding as much as possible any refractive deviation, that is to avoid the need of postoperative glasses, in order to achieve optimal functioning of MIOL and thus reduce the likelihood of adverse postoperative visual phenomena $[17,18]$.

In 2018, a new trifocal MIOL was introduced with a novel design that, according to the manufacturer, could improve the visual quality that is obtained with the trifocal lenses. This is the Acriva Trinova MIOL, designed by sinusoidal functions that produces significantly softer lens surface profiles than the diffraction pattern superimposed with sharp edges of the rest of the trifocal lenses. The Acriva Trinova profile seems to provide better contrast sensitivity and visual dynamics at all distances with a significant reduction in the appearance of postoperative adverse visual effects (A). The objective of this prospective study, carried out in a single center was to evaluate and compare the visual results, contrast sensitivity and patient satisfaction obtained with FineVision and Acriva Trinova trifocal.

\section{Material and methods}

This nonrandomized prospective clinical study included patients who underwent bilateral lens surgery and were scheduled to receive one of two types of MIOL, Acriva Trinova trifocal in 20 eyes and FineVision in 20 eyes out of a total of 20 patients. IOL power was for FineVision 21.89D $\pm 2.52(26.00-18.00)$ and for Acriva Trinova 22.75D \pm 1.67 $(25.00$ - 19.50). Patients with visually significant cataracts who sought the greatest possible independence of lenses for distant, intermediate and near vision and had less than $1 \mathrm{D}$ of astigmatism were included. Before surgery, patients had been interviewed regarding their daily visual activities, with special attention to their intermediate and close needs. Depending on the result, MIOL was chosen to be implanted in both eyes of each patient. FineVision model was implanted in those patients with greater interest in near vision and Acriva Trinova was implanted in people most interested in intermediate vision.

The study was conducted in accordance with the principles of the Declaration of Helsinki and all patients signed a written informed consent before beginning the study.

The study was approved by the local ethics committee.

We included patients, aged between 50 and 79 years, with no ocular pathology other than cataract and with normal visual acuity. Exclusion criteria included amblyopia, axial length greater than $25 \mathrm{~mm}$, previous ocular surgery, including corneal or refractive surgery, keratoconus, endothelial alteration, chronic or recurrent uveitis, acute internal or external infectious ocular pathology, glaucoma, diabetic retinopathy, intraocular pressure higher than $24 \mathrm{mmHg}$, pseudoexfoliation, pathological miosis, alterations of the macula or optic nerve, active inflammation, alteration of the cognitive level that could affect the measurement of visual acuity, interval of more than three months between the date of surgery of the first and second eye and not reaching corrected visual acuity for far (CDVA, Corrected Distance Visual Acuity) postoperatively equal to $20 / 20$ or higher. Patients were informed of possible need for postoperative optical correction, possible loss of contrast in scotopic conditions and optimization of ambient light to optimize postoperative visual performance.

\section{Clinical protocol}

Before surgery, all patients underwent a general ophthalmological examination that included the measurement of mono and binocular Visual Acuity (VA) in mesopic conditions (luminances between $0.25-3 \mathrm{~cd} / \mathrm{m}^{2}$ ), Uncorrected Distance Visual Acuity (UDVA,) and best Corrected Distance Visual Acuity (CDVA), without pupillary dilatation and having verified the absence of postoperative circumstances that could limit CDVA. As optotypes those from EDTRS (Early Treatment Diabetic Retinopathy Study) were used. Photopic and mesopic pupilometry, optical biometry (Lenstar 9000 Haag Streit, AG. Koenig, Switzerland), subjective and objective refraction, biomicroscopy, Goldmann applanation tonometry were performed and corneal topography (Sirius, CSO, Italy).

The power of IOL and the prediction of refraction were based on data measured with Lenstar 9000 (Haag Streit, AG. Koenig, Switzerland) biometer and were calculated using Haigis formula. The IOL power closest to the postoperative emmetropic prediction was selected. Each MIOL model was assigned to each patient based on the outcome of the preoperative interview. Acriva Trinova was assigned to patients with preferred visual activity for intermediate vision and to the rest, FineVision.

In the postoperative period patients were examined at 24 hours, at one month and at 3 months. At the last visit, in addition to the biomicroscopic evaluation with slit lamp and tonometer, the absence of postoperative circumstances that could limit the CDVA was verified; UDVA and CDVA were examined monocular 
and binocular. Optotypes were presented at six meters. The same optotype was used in all patients. VA was measured at intermediate distances $(60 \mathrm{~cm})$ without distance correction (UIVA, uncorrected Intermediate Visual Acuity) and with distance correction (DCIVA, Distance Corrected Intermediate Visual Acuity) and for short distances $(40 \mathrm{~cm})$ without distance correction (UNVA, Uncorrected Near Visual Acuity) and with the best correction for distance (DCNVA, Distance Corrected Near Visual Acuity). To avoid the memorization of letters of the optotypes by the patients, different letters were presented randomly at each visit.

Visual performance was examined by measuring contrast sensitivity for far under mesopic conditions $\left(3 \mathrm{~cd} / \mathrm{m}^{2}\right)$. The detection threshold for different spatial frequencies or contrast sensitivity was examined binocularly, in mesopic conditions, with the best spherocylindrical correction for far using the CSV1000 E test (VectorVison, Dayton, USA). To determine the visual performance of the implants, defocus curves were made with best Corrected Distance Visual Acuity (CDVA) in logarithmic notation (LogMAR). It was performed by measuring the visual acuity monocularly at 6 meters starting from the correction for far and progressively defocusing with positive and negative lenses in half diopter steps from -5.00 to $+3.00 \mathrm{D}$.

Finally, the degree of satisfaction of patients was assessed at the end of the last visit at three months. The patients completed a satisfaction questionnaire that scored from 0 to 5 in increasing degree of difficulty addressing possible adverse visual phenomena and the degree of spectacles independence for different distances. Before the delivery of the questionnaire, the different questions were explained to the patients, leaving them alone to complete a questionnaire that contained the following questions:

1) Do you have vision of halos or glare?

2) Can you read the small print of a newspaper without spectacles?

3) Can you see at intermediate distance, like a computer, without glasses?

4) Can you see for far, like television or driving, without spectacles?

5) What is your general degree of satisfaction.

\section{Intraocular lenses}

Finevision micro F model: FineVision Micro F lens (PhySiol Liege, The Nederlands) is a one-piece MIOL and four closed haptic, fenestrated, aspherical (spherical aberration of -0.11 microns), diffractive, trifocal, made of acrylic material, $25 \%$ hydrophilic. The maximum diameter of this MIOL is 10.75 $\mathrm{mm}$ and a $6.15 \mathrm{~mm}$ optics. MIOL is available in powers of +10.00 to +35.00 diopters (D) in steps of $0.50 \mathrm{D}$. The power for intermediate vision is $1.75 \mathrm{D}$ and for near is $3.50 \mathrm{D}^{\mathrm{B}}$. Optics, designed from computational theoretical equations, is the result of a combination of two independent diffractive MIOL giving rise to a unique diffractive pattern [12], with an asymmetric distribution of light between the three resulting foci; for an IOL of $20 \mathrm{D}$ and with a pupil diameter of $3 \mathrm{~mm}$, the distribution of light and energy for far, near and intermediate vision is $42 \%, 29 \%$ and $15 \%$ respectively. Approximately $14 \%$ of the light energy is lost because it is reached with high diffraction orders, compared with $18 \%$ that is lost with an IOL with typical bifocal refractive design [19]. As the pupil diameter increases, the fine-tuned optics of FineVision increase the percentage of light directed at far vision.

\section{Acriva trinova model}

The newly introduced Acriva Trinova (VSY Biotechnology, The Nederlands) lens (2018) is a one-piece MIOL, with a plate haptic, aspheric and achromatic, diffractive, trifocal, hydrophobic surface design. The maximum diameter is 11.00 $\mathrm{mm}$ and that of its optics is $6.00 \mathrm{~mm}$. Available in powers from 0.00 to $+32.00 \mathrm{D}$ in steps of $0.5 \mathrm{D}$. The power for intermediate vision is $1.50 \mathrm{D}$ and for next is $3.0 \mathrm{D}$. The shape of the optics of the lens derives from a sinusoidal function resulting in profiles of smoothed progression surface. According to the manufacturer, the percentage of light transmission in photopic conditions is $41 \%$ far, $30 \%$ intermediate and $29 \%$ close; in mesopic is $45 \%$ far, $25 \%$ intermediate and $30 \%$ for near A.

\section{Surgical technique}

All surgeries were performed under topical anesthesia by a single surgeon (AC) using a sutureless phacoemulsification technique with $2.2 \mathrm{~mm}$ incision. MIOL were all implanted in the capsular bag by means of an injection system.

The postoperative treatment consisted of steroids and topical antibiotics for two weeks. After stopping the antibiotic the steroid was reduced until it was removed one month after the intervention. Both MIOL were calculated to obtain the emmetropia.

\section{Statistic analysis}

To study the possible differences in visual acuity and contrast sensitivity obtained with both lenses. The quantitative variables were described by the mean, standard deviation and range.

To analyze the results we used the statistical program SPSS. The results with normal parametric tests measured according to the significance ( $p>0.05$ ) of the shapiro-wilk formula for that variable were analyzed by measuring the means and the standard deviation. To calculate the $\mathrm{p}$ value, we compared both means with a Student's T-test for independent samples. We analyzed the possible differences between 8 variables, 6 independent quantitative variables of each of the two types of MIOL to study and 2 qualitative variables according to the MIOL type.

For non-normal tests according to the shapiro-wilk formula ( $\mathrm{p}<0.05)$, we calculated percentiles (p25 / p50 / p75) and to calculate the value of $\mathrm{p}$ we applied nonparametric tests, then we used the U test of Mann Whitney for independent samples. 


\section{Results}

A total of 40 eyes of 20 patients with an age range between 48 and 68 years were evaluated in our study. Each of the two groups was made up of 20 eyes in which the same MIOL model was implanted bilaterally. In both groups the average age was $59.60 \pm 7.32(50 / 68)$.

\section{Visual results}

In postoperative refraction the mean postoperative spherical equivalent was different between both groups. In FineVision group $-0.05 \mathrm{D} \pm 0.24(-0.88 /+0.51)$ and in Acriva Trinova it was $0.2 \mathrm{D} \pm 0.6(-0.50 /+1.50)(\mathrm{p}=0.02)$.

Table 1 summarizes the visual postoperative results with both two MIOL types.

In far vision a similar binocular CDVA was achieved with both MIOLs.

In the intermediate vision the Acriva Trinova stood out slightly for binocular and monocular DCIVA. These differences were not statistically significant.

Regarding near visual acuity, a significant lower binocular DCNVA was achieved with the Acriva Trinova model $(p=0.033)$.

Results of contrast sensitivity.

Table 2 summarizes all the results of the contrast sensitivity measurement in both groups.

For spatial frequencies A, B and D, FineVision MIOL showed a better average performance for the average contrast sensitivity compared to Acriva Trinova MIOL. For the spatial frequency C, the Acriva Trinova MIOL showed better average performance compared to the FineVision MIOL. None of these differences in the mean obtained was statistically significant.

In Figure 1 we can see how both groups of MIOL achieved contrast sensitivity results within the range of physiological contrast sensitivity established for the measurement device used in this study for normal patients of similar age.

Results of satisfaction questionnaires.

Figures 2,3 present results of the satisfaction questions made to each patient with each of the MIOLs models at the third postoperative month.

The self-assessment questionnaires were carried out on uncorrected patients. In regard to halos and glare, the degree of satisfaction was approximately equal in both groups. From $20 \%$ to $30 \%$ did not perceived halos or glare, between $20 \%$ and $40 \%$ complained from mild to moderate difficulties. And $20 \%$ to $30 \%$ had high difficulty. In no group very high or unacceptable difficulty were appreciated (Figures 2,3).

For reading tasks without correction, however, all patients with Acriva Trinova had no difficulty compared with $40 \%$ with FineVision. A patient with FineVision reported severe difficulty for reading without correction (Figure 2).
Table 1: UDVA uncorrected distance visual acuity, CDVA corrected distance visual acuity, UIVA uncorrected intermediate visual acuity, DCIVA distance corrected intermediate visual acuity, UNVA uncorrected near visual acuity, DCNVA distance corrected near visual acuity.

\begin{tabular}{|c|c|c|c|c|}
\hline & $\begin{array}{c}\text { VA Results } \\
\text { (VA logMar } \pm \text { SD) }\end{array}$ & $\begin{array}{c}\text { Grup-1 } \\
\text { FineVision }\end{array}$ & $\begin{array}{c}\text { Grup-2 } \\
\text { Acriva Trinova }\end{array}$ & p value \\
\hline \multirow[b]{2}{*}{ UDVA } & Monocular (p25-p75) & $0.1 \pm 0.13$ & $0.11 \pm 0.12$ & 0,437 \\
\hline & Binocular & $0.05 \pm 0.08$ & $0.06 \pm 0.11$ & 0,999 \\
\hline \multirow[b]{2}{*}{ CDVA } & Monocular & $0.01 \pm 0.02$ & $0.06 \pm 0.07$ & 0,768 \\
\hline & Binocular & $0.01 \pm 0.01$ & $0.01 \pm 0.02$ & 0,999 \\
\hline \multirow[b]{2}{*}{ UIVA } & Monocular & $0.23 \pm 0.19$ & $0.18 \pm 0.14$ & 0,422 \\
\hline & Binocular & $0.14 \pm 0.16$ & $0.11 \pm 0.07$ & 0,857 \\
\hline \multirow[b]{2}{*}{ DCIVA } & Monocular (p25-p75) & $0.18 \pm 0.19$ & $0.14 \pm 0.07$ & 0,709 \\
\hline & Binocular & $0.14 \pm 0.21$ & $0.11 \pm 0.08$ & 0,530 \\
\hline \multirow[b]{2}{*}{ UNVA } & Monocular & $0.10 \pm 0.17$ & $0.17 \pm 0.05$ & 0,050 \\
\hline & Binocular & $0.03 \pm 0.07$ & $0.13 \pm 0.02$ & 0,030 \\
\hline \multirow[b]{2}{*}{ DCNVA } & Monocular & $0.04 \pm 0.05$ & $0.16 \pm 0.06$ & 0,020 \\
\hline & Binocular & $0.01 \pm 0.04$ & $0.09 \pm 0.07$ & 0,033 \\
\hline
\end{tabular}

Table 2: Sensibility Contrast Results of two Trifocal IOL groups at three months postsurgery.

\begin{tabular}{|l|l|l|l|}
\hline $\begin{array}{l}\text { Contrast Sensibility Results (cpd) with } \\
\text { CDVA in mesopics conditions }\end{array}$ & $\begin{array}{l}\text { Grup -1 } \\
\text { FineVision }\end{array}$ & $\begin{array}{l}\text { Grup -2 } \\
\text { Acriva } \\
\text { Trinova }\end{array}$ & p value \\
\hline A & $5,71(1,49)$ & $5,60(0,89)$ & 0,833 \\
\hline B & $5,86(0,90)$ & $4,80(1,09)$ & 0,096 \\
\hline C & $5,29(2,36)$ & $5,80(1,64)$ & 0,685 \\
\hline D & $4,86(1,86)$ & $4,80(0,83)$ & 0,951 \\
\hline
\end{tabular}

* CDVA corrected distance visual acuity. Cicles per degree (Cpd) (standard deviation); $t$ : Spacial Frecuency of $3,6,12$ y 18 cicles/grades for A B C D respectively

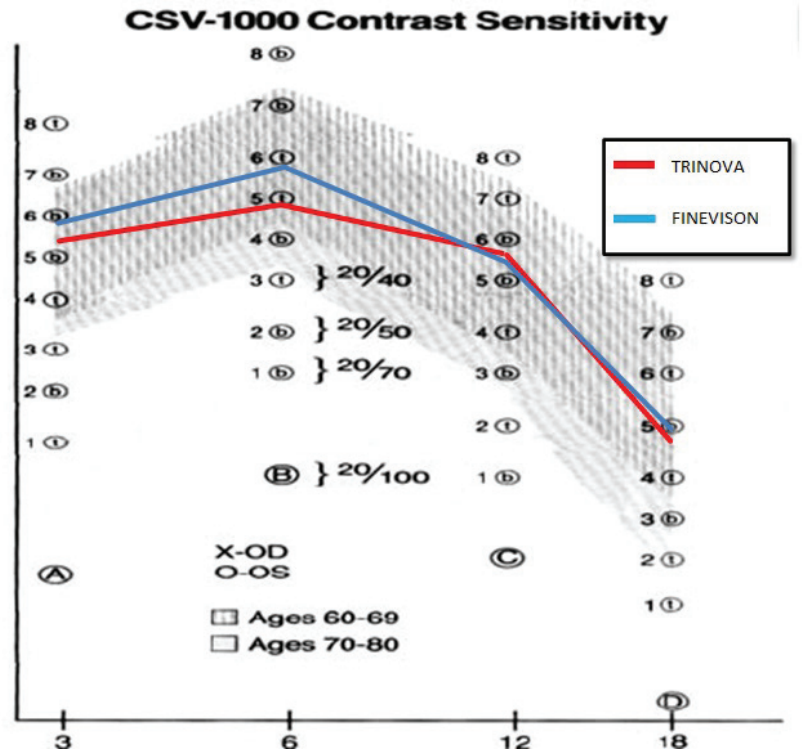

Figure 1: Contrast Sensibility measured with CSV-1000E Test (VectorVision Dayton. EEUU) for differents spatials frequencies (Cicles per degree) three months postsurgery. Gray area shows minimum and maximum values reported for normal subjects in an age range between 60 to 80 years old. FineVision in Blue line, Acriva Trinova in red line.

For intermediate distance, such as reading computer without correction, $100 \%$ of patients with Acriva Trinova had no difficulty compared to $60 \%$ of patients with Fine Vision.

Citation: Amigo-Frances A, Castillo-Gomez A, Carmona-Gonzalez D, Martinez-Sorribes P, Amigó A (2020) Comparative study of visual results obtained with two Trifocal lens models in cataract surgery. J Clin Res Ophthalmol. 7(2): 054-060. DOI: https://dx.doi.org/10.17352/2455-1414.000074 
In order to evaluate far vision without glasses, $80 \%$ of both groups referred having no difficulty whatsoever (Figures 2,3).

Finally, in terms of the degree of general satisfaction, with Finevision no patient was totally satisfied, as there were $80 \%$ that referred some degree of dissatisfaction. In one case the degree of dissatisfaction was maximum (Figure 2). For Acriva Trinova $60 \%$ was fully satisfied while $40 \%$ oscillated between varying degrees of dissatisfaction (Figure 3 ).

\section{Defocus curve}

Defocus curve results, performed with the best correction for far, showed a higher tolerance to hypermetropic refraction with Acriva Trinova. In emetropized patients, visual performance in terms of visual acuity for distance was similar in both MIOLs. In intermediate vision AcrivaTrinova had a

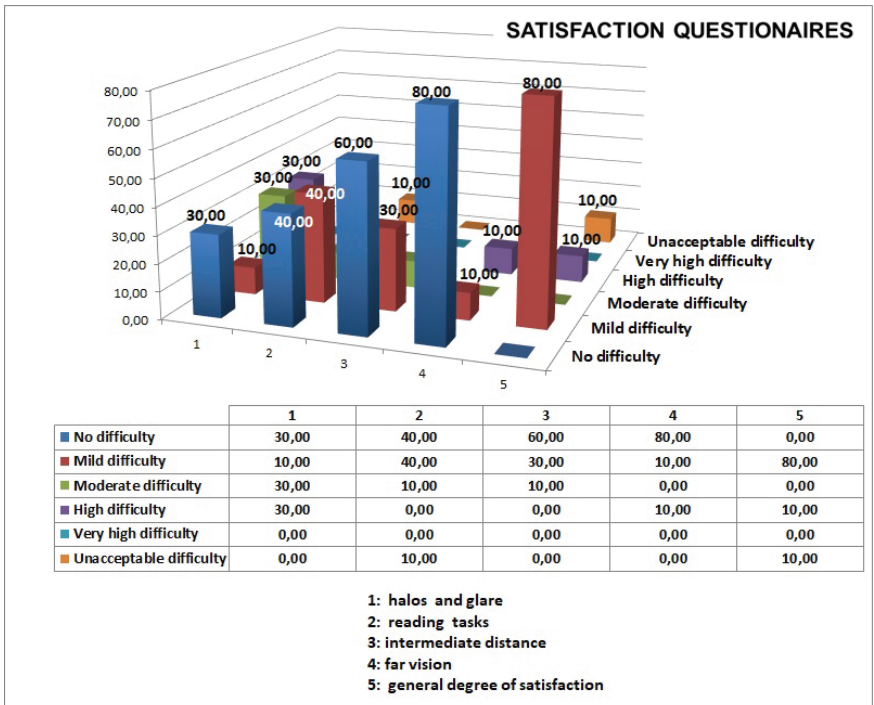

Figure 2: Satisfaction Questionaires results in patients implanted with FineVision MIOL.

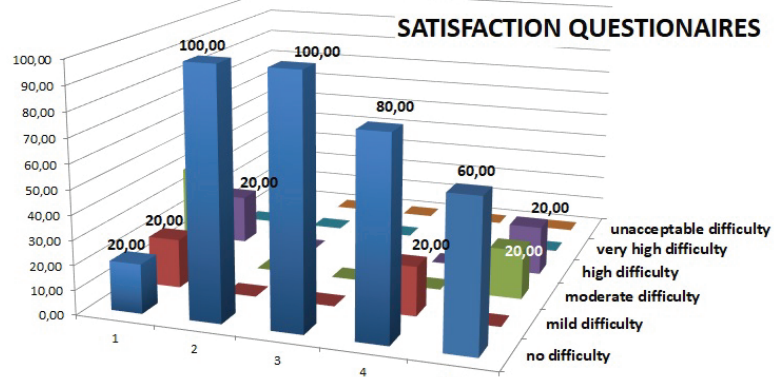

\begin{tabular}{|c|c|c|c|c|c|}
\hline & 1 & 2 & 3 & 4 & 5 \\
\hline Ino difficulty & 20,00 & 100,00 & 100,00 & 80,00 & 60,00 \\
\hline mild difficulty & 20,00 & 0,00 & 0,00 & 20,00 & 0,00 \\
\hline I moderate difficulty & 40,00 & 0,00 & 0,00 & 0,00 & 20,00 \\
\hline Wigh difficulty & 20,00 & 0,00 & 0,00 & 0,00 & 20,00 \\
\hline very high difficulty & 0,00 & 0,00 & 0,00 & 0,00 & 0,00 \\
\hline I unacceptable difficulty & 0,00 & 0,00 & 0,00 & 0,00 & 0,00 \\
\hline
\end{tabular}

\section{1: halos and glare}

2: reading tasks

3: intermediate distance
5: general degree of satisfaction

Figure 3: Satisfaction Questionaires results in patients implanted with FineVision MIOL.

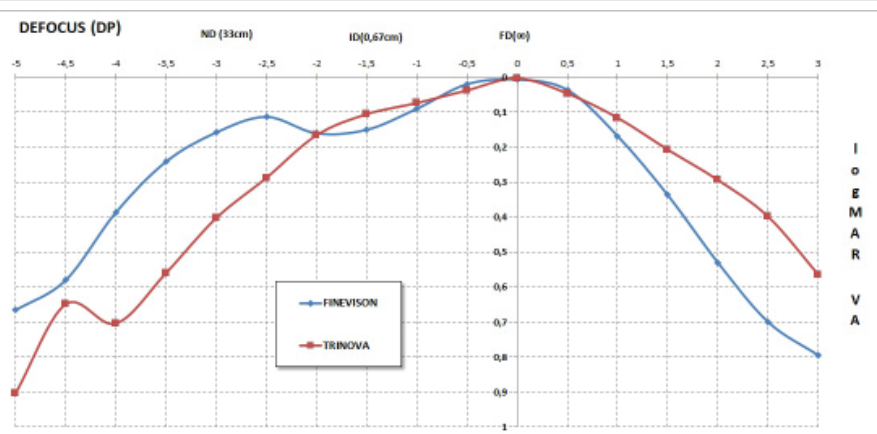

Figure 4: Defocus curve average results obtained with FineVision (blue line) versus Acriva Trinova (red line). ND: Near Distance; ID: Intermediate Distance. FD: Far Distance.

slightly superior performance to FineVision. For near distance FineVision showed the best performance in the defocus curve (Figure 4).

\section{Discussion}

The activities for which intermediate vision is required have gained importance rapidly in recent decades. Among others, the use of computers or tablets has spread significantly among all age sectors of the world's population. For these activities, bifocal MIOLs are probably not the best choice when implanting intraocular lenses.

Trifocal MIOLs have been introduced aiming to obtain independence for far, near and also intermediate vision without glasses [12,13].

In particular FineVision MIOL solves some of the limitations of traditional bifocal diffractive MIOLs by offering good visual results including good intermediate vision [20] and accurate refractive predictability calculation, providing generally a high level of satisfaction [3,13,15,21-23].

Unlike FineVision, we have not been able to find published results of the second trifocal MIOL model we have studied, Acriva Trinova IOL, except an anecdotal communications in scientific meeting (Stodulka P. Clinical results of implantation of the new sinusoidal trifocal lens. Presented at: European Society of Cataract and Refractive Surgeons meeting, Sept. 22-26, 2018, Vienna). This communication presented visual results obtained without the best correction for far and given the significant refractive deviation from emmetropia obtained; these results offered a limited information about AcrivaTrinova performance under emetropic conditions.

The purpose of this work was to describe, in terms of visual acuity, contrast sensitivity, possible dysphotopsic phenomena and patient satisfaction; the performance of the MIOL Acriva Trinova comparing it with the better known MIOL FineVision in emmetropic conditions for both lenses. To our acknowledge this is the first retrospective comparative study of the results of these two different trifocal IOLs.

Possibles limitations of this study have been the relatively

Citation: Amigo-Frances A, Castillo-Gomez A, Carmona-Gonzalez D, Martinez-Sorribes P, Amigó A (2020) Comparative study of visual results obtained with two Trifocal lens models in cataract surgery. J Clin Res Ophthalmol. 7(2): 054-060. DOI: https://dx.doi.org/10.17352/2455-1414.000074 
short follow-up time that could limit in some patients a complete neuroadaptation to multifocality, the use of one non validated satisfaction test and the small sample size. Regarding follow-up time, there are other publications in which an adjustment time of 3 or 4 months is considered sufficient for a complete neuroadaptation $[20,23]$.

In our cases, a large majority of patients at three months of surgery had achieved a degree of complete visual adaptation with both trifocal lenses as reflected in the satisfaction tests (Figures 2 and 3). Regarding the satisfaction test there is a clear shortage of standardized tests and especially of tests directed to the assessment of the degree of satisfaction after MIOL implantation. In this study we included patients aged between 50 and 79 years. The aim was to search for an age range where senile cataract is prevalent, as well as to avoid patients who, due to possible senile cognitive changes, could present greater difficulties in visual adaptation to a multifocal lens. In relation to the small sample size of this study we want to stress that when we decided to study the visual results of Acriva Trinova, at our acknowledge there was a lack of significant previous publications in regard to visual results of this lens on that moment. Therefore, we designed our comparative study as a pilot study implanting Acriva bilaterally only in ten patients. Even with the small sample of 20 Acriva Trinova studied, with the statistical method adequate for small samples that we have used, statistically significant differences have been obtained with small standard deviations. These data encourage us to continue implanting Acriva Trinova and to carry out future studies with larger sample sizes.

Obtained visual results confirm previous investigations with FineVision $[13,15,21-23]$ and provide information that we believe, until now, inexistent about the comparative results with the Acriva Trinova.

Given statistically significant differences in obtained postoperative spherical equivalent between both lenses, the comparison of the visual results measured without the best far correction it would have not been very valuable in terms of aim from this study. Therefore we will focus on the visual results measured with the best correction for far (CDVA) because this way we will be comparing both MIOL in equal optical conditions which is the intended emmetropia. With the data obtained in this study, we can conclude by comparing the CDVA of the different MIOL models, that both offered a correct far distance vision with correction (Table 1).

We found a slight disparity for intermediate vision (DCIVA) in favor of Acriva Trinova, although this difference was not statistically significant. This small difference can probably be due to the unequal addition of both lenses, $1.75 \mathrm{D}$ in the FineVision lens with focal length $56 \mathrm{~cm}, 1.50 \mathrm{D}$ in the Acriva Trinova whose focal distance $66 \mathrm{~cm}$.

The monocular and binocular near vision DCNVA showed a better performance with FineVision than with Acriva Trinova (p> 0.05) (Table 1). Once again there is a probable relation between the greater addition for near distance of the first lens (3.50D) compared to the addition of 3.0D of Acriva Trinova. We must also bear in mind that the distribution of light is different between the two MIOLs for near vision ${ }^{\mathrm{A}, \mathrm{B}}$.

The defocus curve of Fine Vision MIOL has been investigated in recent publications $[21,24]$ and coincides with the values we have obtained in this study. We have not found published results of the defocus curve obtained with Acriva Trinova. Our results indicate that there are differences between the defocus curve of both MIOL. These are significant for intermediate distances where Acriva has a better performance probably due to its 1.75D potency that favors it for a focal point of $60 \mathrm{~cm}$. In near distances, the power of $3.50 \mathrm{D}$ of FineVision provides a better performance than the $3.00 \mathrm{D}$ that offers Acriva for near (Figure 4). It is desirable and future studies are expected to provide new defocus curves with Acriva Trinova.

Regarding contrast sensitivity, both lenses were within the range of normality considered for normal population [25], at all spatial frequencies. There were no significant differences in contrast sensitivity obtained with both MIOLs. It seems that at least in regard contrast sensitivity, the unique sinusoidal design that according to the manufacturer softens the optic of Acriva Trinova, is not more efficient than the design of the FineVision.

Satisfaction test (Figures 2,3) showed a relatively high frequency of referred dysphotopsic phenomena and a variable degree of general satisfaction among patients in both MIOL groups. In these results it is important to highlight the possible influence of some residual refractiveerror since the postoperative spherical equivalents in both groups were different and for practical reasons, as it is usual when performing postoperative satisfaction tests, this test was performed without the best optical far correction. This highlights the importance of obtaining precise postoperative results, aiming to avoid any refractive deviation from emmetropia, even subtle, in order to achieve an optimal functioning of the MIOLs and so reducing the likelihood of adverse postoperative visual phenomena $[17,18]$. For this reason, it is likely that the visual complaints of patients implanted with LIOM, that we can find referred in the ophthalmic literature as well as in daily practice, may be due at least in part to refractive residual defects and not to optical characteristics of implanted MIOL.

In conclusion, when postoperative emmetropia was achieved, both types of MIOL showed correct visual performance for far, intermediate and near distances with no differences in contrast sensitivity. There were some differences between the performance of both MIOL, FineVision got a better performance in near vision and Acriva Trinova stood out slightly in intermediate vision. In both groups there were some postoperative dysphotopsic phenomena that in general were described as tolerable. It is possible that to some degree these dysfunctional phenomena were influenced by the presence of postoperative refractive deviations.

\section{References}

1. Eurostat - Surgical operations and procedures statistics. Link: https://bit.ly/3jbDCBN 
2. Calladine D, Evans JR, Shah S, Leyland M (2012) Multifocal versus monofocal intraocular lenses after cataract extraction. Cochrane Database Syst Rev 12 : CD003169. Link: https://bit.ly/3h12GJy

3. Cochener B, Boutillier G, Lamard M, Auberger-Zagnoli C (2018) A Comparative Evaluation of a New Generation of Diffractive Trifocal and Extended Depth of Focus Intraocular Lenses. J Refract Surg 34: 507-514. Link: https://bit.ly/20oiwl9

4. Montés-Micó R, Madrid-Costa D, Ruiz-Alcozer J, Ferrer-Blasco T, Pons M (2014) In vitro optical quality differences between multifocal apodized diffractive intraocular lenses. J Catarat Refract Surg 40: 60-69.

5. Alió JL, Plaza-Puche AB, Piñero DP, Amparo F, Rodriguez-Prats JL, et al (2011) Quality of life evaluation after implantation of 2 multifocal intraocular lens models and a monofocal model. J Cataract Refractive Surgery 37: 638648. Link: https://bit.ly/3j11ZSq

6. Lane SS, Morris M, Nordan L, Packer M, Tarantino N, et al. (2006) Multifocal intraocular lenses. Ophthalmol Clin North Am 19: 89-105. Link: https://bit.ly/2DKjZAn

7. Cochener B, Lafuma A, Khoshnood B, Courouve L, Berdeaux G (2011) Comparison of outcomes with multifocal intraocular lenses: a meta-analysis. Clin Ophthalmol 5: 45-56. Link: https://bit.ly/3fBvSXy

8. Petermeier K, Messias A, Gekeler F, Szurman P (2011) Effect of +3.00 diopter and +4.00 diopter additions in multifocal intraocular lenses on defocus profiles, patient satisfaction, and contrast sensitivity. J Cataract Refract Surg 37: 720-726. Link: https://bit.ly/3iYy6Cl

9. Shen Z, Lin Y, Zhu Y, Liu X, Yan J, et al. (2017) Clinical comparison of patient outcomes following implantation of trifocal or bifocal intraocular lenses: a systematic review and meta-analysis. Sci Rep 7: 45337. Link: https://bit.ly/2B3ZOHQ

10. Liu X, Xie L, Huang Y (2018) Comparison of the Visual Performance After Implantation of Bifocal and Trifocal Intraocular Lenses Having an Identical Platform. J Refract Surg 34: 273-280. Link: https://bit.ly/3jeCrBw

11. Mojzis P, Kukuckova L, Majerova K, Liehneova K, Piñero DP (2014) Comparative Analysis of the Visual Performance After Cataract Surgery With Implantation of a Bifocal or Trifocal Diffractive IOL. J Refract Surg 30: 666672. Link: https://bit.ly/20ppQx3

12. Gatinel D, Pagnoulle $C$, Houbrechts $Y$, Gobin $L$ (2011) Design and qualification of a diffractive trifocal optical profile for intraocular lenses. J Cataract Refract Surg 37: 2060-2067. Link: https://bit.ly/391dMvA

13. Carballo-Alvarez J, Vazquez-Molini JM, Sanz-Fernandez JC (2015) Visual outcomes after bilateral trifocal diffractive intraocular lens implantation. BMC Ophthalmol 14: 26. Link: https://bit.ly/2Zu7nFV

14. Gatinel D, Loicq J (2016) Clinically relevant optical properties of bifocal, trifocal, and extended depth of focus intraocular lenses. J Refract Surg 32: 273-280. Link: https://bit.ly/32fWLfH

15. Sheppard AL, Shah S, Bhatt U, Bhogal G, Wolffsonn JS (2013) Visual outcomes and subjective experience after bilateral implantation of a new diffractive trifocal intraocular lens. J Cataract Refract Surg 39: 343-349. Link: https://bit.ly/30eN4vp

16. de Vries NE, Webers CA, Touwslager WR, Bauer NJC, de Brabander J, et al. (2011) Dissatisfaction after implantation of multifocal intraocular lenses. J Cataract Refract Surg 37: 859-865. Link: https://bit.ly/3epHFXm

17. Martínez Palmer A, Gómez Faiña $P$, España Albelda A, Comas Serrano $M$ Nahra Saad D, et al. (2008) Visual function with bilateral implantation of monofocal and multifocal intraocular lenses: a prospective, randomized, controlled clinical trial. J Refract Surg 24: 257-264. Link: https://bit.ly/3j0jFOF
18. de Vries NE, Nuijts RM (2013) Multifocal intraocular lenses in cataract surgery: literature review of benefits and side effects. J Cataract Refract Surg 39: 268 278. Link: https://bit.ly/32ietix

19. Davidson JA, Simpson MJ (2006) History and development of the apodized difractive intraocular lens. J catartact Refractive Surg 32: 849-858. Link: https://bit.ly/2CbRtHq

20. Gundersen KG, Potvin R (2017) Trifocal intraocular lenses: a comparison of the visual performance and quality of vision provided by two different lens designs. Clin Ophthalmol 11: 1081-1087. Link: https://bit.ly/2B54HoY

21. Plaza-Puche AB, Alio JL (2016) Analysis of defocus curves of different modern multifocal intraocular lenses. Eur J Ophthalmol 26: 412-417. Link: https://bit.ly/2CynB7W

22. Martinez-de-la-Casa JM, Carballo-Alvarez J, Garcia-Bella J, Vazquez-Molin JM, Morales L, et al. (2017) Photopic and mesopic performance of 2 different trifocal diffractive intraocular lenses. Eur J ophthalmology 27: 26-30. Link: Link: https://bit.ly/32hLj30

23. Bilbao-Calabuig R, Llovet-Rausell A, Ortega-Usobiaga J, Martínez-Del-Pozo M, Mayordomo-Cerdá F, et al. (2017) Visual Outcomes Following Bilateral Implantation of Two Diffractive Trifocal Intraocular Lenses in 10.084 Eyes. Ophthalmol 179: 55-66. Link: https://bit.ly/30amCmG

24. Ruiz-Mesa R, Abengózar-Vela A, Ruiz-Santos MA (2017) Comparative study of the visual outcomes between a new trifocal and an extended depth of focus intraocular lens. Eur J Ophthalmol 28. Link: https://bit.ly/30ess6e

25. Hohberger B, Laemmer R, Adler W, Juenemann AG, Horn FK (2007) Measuring contrast sensitivity in normal subjects with OPTEC 6500: influence of age and glare Graefes Arch Clin Exp Ophthalmol 245: 1805-1814. Link: https://bit.ly/2ZrVal9

\section{Discover a bigger Impact and Visibility of your article publication with Peertechz Publications}

\section{Highlights}

* Signatory publisher of ORCID

* Signatory Publisher of DORA (San Francisco Declaration on Research Assessment)

* Articles archived in worlds' renowned service providers such as Portico, CNKI, AGRIS, TDNet, Base (Bielefeld University Library), CrossRef, Scilit, J-Gate etc.

* Journals indexed in ICMJE, SHERPA/ROMEO, Google Scholar etc.

* OAI-PMH (Open Archives Initiative Protocol for Metadata Harvesting)

* Dedicated Editorial Board for every journa

* Accurate and rapid peer-review process

* Increased citations of published articles through promotions

* Reduced timeline for article publication

Submit your articles and experience a new surge in publication services (https://www.peertechz.com/submission).

Peertechz journals wishes everlasting success in your every endeavours.

Copyright: @ 2020 Amigo-Frances A, et al. This is an open-access article distributed under the terms of the Creative Commons Attribution License, which permits unrestricted use, distribution, and reproduction in any medium, provided the original author and source are credited.

Citation: Amigo-Frances A, Castillo-Gomez A, Carmona-Gonzalez D, Martinez-Sorribes P, Amigó A (2020) Comparative study of visual results obtained with two Trifocal lens models in cataract surgery. J Clin Res Ophthalmol. 7(2): 054-060. DOI: https://dx.doi.org/10.17352/2455-1414.000074 